\title{
Viral infections in renal allograft recipients treated with long-term immunosuppression
}

\author{
EDWIN S SPENCER, H KERZEL ANDERSEN
}

British Medical fournal, 1979, 2, 829-830

\section{Patients and methods}

Patients who had received kidney grafts in the period November 1964 to January 1972 were traced during the spring and summer of 1977. These patients were part of a group of 100 patients monitored

\section{Summary and conclusions}

Thirty-nine renal allograft recipients who had received continuous immunosuppression for six to 13 years were examined clinically and virologically for evidence of past or present viral infection. Twenty-five had common warts, usually on the hands. In most the warts had appeared about one year after transplantation; once present, they never disappeared. Six patients had had a zoster rash from two months to four years after transplantation. None had had jaundice, and there was no change in the frequency of colds or non-specific febrile illness. Four patients had no cytomegalovirus complement-fixing antibodies throughout the observation period; in the other 35 the antibody titre had risen appreciably during the first three to four months after transplantation. Antibody titres were high (mean 64) at follow-up, being only slightly lower than the highest titres achieved during the immediate postoperative period. None of the patients had had symptomatic cytomegalovirus infection, and in only two was the virus isolated from the urine at follow-up; the titres were extremely low. No changes occurred in the frequency of herpes simplex eruptions. Although all patients had herpes simplex humoral antibody, none excreted the virus.

Although cytomegalovirus antibody titres were high, virus excretion was rare, indicating that chronic cytomegalovirus infection in these patients is immunologically well controlled.

\section{Introduction}

Several centres have reported viral infections in patients treated with a combination of glucocorticoid steroids and cytotoxic agents. This combination of drugs is widely used to prevent rejection of foreign-tissue transplants. With the ever increasing numbers of people receiving kidney transplants, patients being treated with immunosuppressive regimens are by no means rare. Infections with the herpes group of viruses are common during the first few months after kidney transplantation. ${ }^{1-3}$ Relatively little, however, has been reported about viral infections occurring after this time. In this study a group of renal allograft recipients who had received continuous immunosuppressive treatment for six to 13 years was evaluated clinically and virologically for present or past viral disease.

\footnotetext{
Medical Department C, Århus Kommunehospital and Institute of Medical Microbiology, Århus University, Århus, Denmark

EDWIN S SPENCER, MD, PHD, associate professor of internal medicine and consultant internist intensively for cytomegalovirus infections during the first two years after transplantation. ${ }^{3}$ Of the original 100 patients, 38 had died and in an additional 16 the graft had failed. We could not trace seven patients, four of whom had had clinically apparent cytomegalovirus infe-tion after transplantation. The remaining 39 patients ranged in age from 25 to 63 years (average 45 ) and consisted of 22 men and 17 women. All were receiving maintenance immunosuppression with $1.25-5 \mathrm{mg}$ prednisone and $25-150 \mathrm{mg}$ azathioprine daily. The azathioprine dose corresponded to $2 \mathrm{mg} / \mathrm{kg}$ body weight unless anaemia or leucopenia necessitated a lower dose.

All patients were interviewed by one of us (ESS) and asked whether they had had warts, colds, influenza, jaundice, shingles, cold sores, or any other viral disease, such as measles, rubella, mumps, and chicken pox. Any lesions were examined and descriptions of past disease obtained from clinical records.

Excretion of cytomegalovirus and herpes simplex virus was tested in each patient by inoculating throat swabs and urine on human embryo cell cultures as described. ${ }^{1}$ Further tests for viraemia due to these viruses were done by inoculating leucocytes, lymphocytes, erythrocytes, and plasma on cell cultures. The cells were separated from heparinised blood specimens on Ficall gradients as described elsewhere. ${ }^{4}$ The cultures were observed for cytopathic changes for one month.

\section{Results}

All patients were in good health at examination, and none had skin lesions other than warts. No patients had had jaundice. None had noted a greater tendency to develop colds after transplantation, most having had two or three a year. Ten were subject to recurrent cold sores; two thought they had had more and one fewer attacks than before transplantation. Fourteen had had a febrile illness with muscular aches and dry cough without rhinitis. Ten of these patients were admitted to hospital, and in each case fever subsided in a few days without treatment; in no case was there serological evidence of influenza A or B, adenovirus, Epstein-Barr virus, or cytomegalovirus infection. Six patients had had shingles. In three the rash appeared within the first three months after transplantation, while in the other three it appeared about four years after transplantation. No patient had had two attacks, and in all the course was typical and benign, a few dermatomes on one side of the body being affected and no dissemination taking place.

None of the patients had had a symptomatic cytomegalovirus infection. In 35 the cytomegalovirus antibody titre had increased appreciably during the first three to four months after transplantation and thereafter complement-fixing titres had remained unchanged (mean 64). Four patients were permanently seronegative. At follow-up six to 13 years after transplantation cytomegalovirus was detected in the urine of only two patients, and then in extremely low titres. In no case could virus be isolated from throat swabs or blood cells.

Twenty-five patients had warts: nine had just one or two a year, but in the others the lesions were continuous and numerous, especially on the hands. In three warts presented a serious cosmetic problem. Warts first appeared from one to four years after transplantation, and only one patient had a single lesion. In the others the warts recurred and the patients were never free of them. In one patient, a 52-year-old man, a tumour appearing among several typical common warts on the back of the hand underwent malignant degeneration and grew rapidly, and histological examination on excision disclosed keratoacanthoma (spinocellular). 


\section{Discussion}

The only two viral infections presenting problems in these patients receiving long-term immunosuppression were shingles and warts. No increase in the number of colds or cold sores occurred, nor was there any remarkable increase in non-specific febrile illness. Of the six patients who had had shingles, three had had early infections-that is, within the first three months after transplantation-while three had had late infections-that is, over three years after transplantation. In all the course was typical and benign. This bi-peaked incidence may indicate two different mechanisms. In a previous study ${ }^{2}$ we found that two out of seven cases of shingles appeared within the first three months, while four occurred from one and a half to two and a half years after transplantation. Our findings are the same in patients receiving long-term and short-term immunosuppression with regard to the great prevalence of warts in these patients. ${ }^{2}$
No late cases of cytomegalovirus disease were seen, and patients who were seronegative three months after transplantation remained so during the whole period of observation (six to 13 years). The high titres seen shortly after immunosuppressive treatment was started remained high for years. Even though titres were high, virus excretion was rare, indicating that chronic cytomegalovirus infection in these patients is immunologically well controlled.

\section{References}

${ }^{1}$ Andersen, H K, and Spencer, E S, Acta Medica Scandinavica, 1969, 186, 7. 2 Spencer, E S, and Andersen, H K, British Medical fournal, 1970, 3, 251. ${ }^{3}$ Spencer, E S, Scandinavian Fournal of Infectious Diseases, 1974, 6, 315.

4 Møller-Larsen, A, et al, Intervirology, 1976, 6, 249.

(Accepted 31 fuly 1979)

\section{SHORT REPORTS}

\section{Oxamniquine fever-drug-induced or immune-complex reaction?}

Oxamniquine, a new schistosomicidal drug, is effective agains schistosomiasis mansoni; it is given by mouth in a dose of 20-30 $\mathrm{mg} / \mathrm{kg} /$ day for three days. The most common side effects are dizziness, drowsiness, and headache. ${ }^{1}$ We report an additional side effectnamely, a characteristic fever-which occurred in 40 out of 106 patients $\left(38^{\circ}{ }_{0}\right)$ given oxamniquine during the past three years. In most cases the temperature rose to $38-39^{\circ} \mathrm{C} 24-72$ hours after completing the three-day course and lasted two to five days before defervescence. Six of the 40 patients also developed a typical Löfflerlike syndrome, with fever, pronounced peripheral blood eosinophilia, and scattered pulmonary infiltrates. Thirty-seven of the 106 treated patients were studied immunologically in an attempt to explain this febrile reaction.

\section{Methods and results}

Thirty-seven male patients aged 7-50 years with varying excretion rates of Schistosoma mansoni eggs (100-2560/g faeces) were studied immunologically. Seventeen of the patients had developed the typical febrile reaction after treatment and 20 (serving as controls) had not. Urinary excretion of schistosomal antigens was assayed by a template agar microimmunodiffusion method $^{2}$ using rabbit antiserum to homologous adult worm extract. All urine specimens were concentrated $30-50$-fold by membrane filtration. The presence of serum circulating immune complexes was assessed by a polyethylene glycol precipitation technique. ${ }^{3}$ All serum samples were assayed at $1 / 5$ dilution in saline, at which dilution normal samples were negative. Specimens of urine and serum were obtained on admission, on days 3 and 14 of treatment, and on discharge.

Of the 37 patients, 23 had increased excretion of antigens (up to five immunoprecipitin bands) in the urine and an increase in immune complexes (optical density $280 \mathrm{~nm}, 0 \cdot 150-0 \cdot 275$ ) in the serum but only 12 of the 23 patients developed the febrile reaction; the other 11 (though showing similar increases in antigen excretion and serum immune complexes) did not develop post-treatment fever.

\section{Comment}

The cause of the fever remains uncertain. In normal, uninfected adults oxamniquine does not invoke fever. ' In Brazil and East Africa patients with schistosomiasis mansoni have been treated with oxamniquine with varying results on fever as a side effect. Coutinho et al, ${ }^{5}$ however, reported the occurrence of fever lasting one to three days in 17 out of 74 patients given oxamniquine but did not emphasise its importance. The high incidence in our series suggests that Egyptian patients handle the drug differently metabolically, leading to a pyrogenic metabolite. Alternatively schistosome immune complexes formed during treatment may bind complement and thus invoke fever. People must differ noticeably, however, in their response to this immunological event. Further investigation is needed to ascertain the presence of either endogenous pyrogen in such patients' plasma or oxamniquine metabolites that can cause fever.

This work formed part of research project MRO41.09.01-0153, NMRDC, NNMC, Bethesda, Md 20014

${ }^{1}$ Omer, A H S, British Medical fournal, 1978, 2, 163.

2 Crowle, A J, Immunodiffusion, 2nd edn, p 289. New York, Academic Press, 1975.

${ }^{3}$ Digeon, M, et al, fournal of Immunological Methods, 1977, 16, 165.

4 Foster, R, Revista do Instituto de Medicina Tropical de Sao Paulo, 1973, 15, suppl No 1, p 1 .

${ }^{5}$ Coutinho, A, Domingues, A L C, and Bonfim, J R A, Revista do Instituto de Medicina Tropical de Săo Paulo, 1973, 15, suppl No 1, p 15.

(Accepted 6 fuly 1979)

Immunology and Tropical Medicine Departments, United States Naval Medical Research Unit No 3, Cairo, AR Egypt

G I HIGASHI, MD, SCD, head of immunology department

Z FARID, MD, DTM\&H, head of tropical medicine department

\section{Gamma-glutamyltransferase activity in ascitic fluid in diagnosis of hepatocellular carcinoma}

Peters et al reported $^{1}$ that five patients with hepatoma had highly significantly increased activities of gamma-glutamyltransferase $(\gamma-G T)$ in ascitic fluid compared with 26 patients with ascites associated with other diseases. Since there was no overlap in the two ranges of values they suggested this test as a useful adjunct in the diagnosis of primary liver cancer.

\section{Patients, methods, and results}

We studied the $\gamma$-GT activity in ascites from five patients with hepatocellular carcinoma, 22 with alcoholic liver cirrhosis, and six with miscellaneous liver diseases (one chronic active hepatitis, one haemochromatosis, two cryptogenic inactive cirrhosis, one Budd-Chiari syndrome, and one metastatic liver disease). We used the method recommended by the Scandinavian Committee on Enzymes. ${ }^{2}$ The table shows that the activity did not differ among the groups. The measurements in the patients with hepatocellular carcinoma were similar to those of Peters et al. ${ }^{1}$ Our patients, like theirs, all had high serum $\alpha$-fetoprotein concentrations. None of their patients had alcoholic cirrhosis (one had alcoholic hepatitis). Since alcoholic liver disease is generally associated with high serum $\gamma$-GT activities 